\title{
Habits as Knowledge Structures: Automaticity in Goal-Directed Behavior
}

\author{
Henk Aarts \\ Eindhoven University of Technology
}

\author{
Ap Dijksterhuis \\ University of Nijmegen
}

\begin{abstract}
This study tested the idea of habits as a form of goal-directed automatic behavior. Expanding on the idea that habits are mentally represented as associations between goals and actions, it was proposed that goals are capable of activating the habitual action. More specific, when habits are established (e.g., frequent cycling to the university), the very activation of the goal to act (e.g., having to attend lectures at the university) automatically evokes the habitual response (e.g., bicycle). Indeed, it was tested and confirmed that, when behavior is habitual, behavioral responses are activated automatically. In addition, the results of 3 experiments indicated that (a) the automaticity in habits is conditional on the presence of an active goal (cf. goal-dependent automaticity; J. A. Bargh, 1989), supporting the idea that habits are mentally represented as goal-action links, and (b) the formation of implementation intentions (i.e., the creation of a strong mental link between a goal and action) may simulate goal-directed automaticity in habits.
\end{abstract}

The majority of people's actions are executed on a routine basis. The better part of the behavioral repertoire is frequently exhibited in the same physical and social environment and has taken on a habitual character (e.g., James, 1890; Ouellette \& Wood, 1998; Triandis, 1980). These habits are extremely useful in that they enable one to perform one's actions in a mindless, automatic fashion. James (1890) emphasized the importance of habits: "We must make automatic and habitual, as early as possible, as many useful actions as we can" (p. 122). James's reasoning was straightforward. The more actions one can delegate to the unconscious, the more room there is to do things that necessarily require conscious processing. Writing an article would be a more difficult affair if typing (and driving, and taking a shower, and even brushing one's teeth) required conscious planning.

Despite a large contemporary literature on automatic processes in social and nonsocial cognition and behavior (e.g., Bargh, 1989, 1997; Hasher \& Zacks, 1979; Norman \& Shallice, 1986; Smith \& Lerner, 1986), the available research on the concept of habit is largely confined to studies in which the role of past behavior was investigated in the context of attitude-behavior models. An im-

Henk Aarts, Department of Psychology and Language, Eindhoven University of Technology, Eindhoven, the Netherlands; Ap Dijksterhuis, Department of Social Psychology, University of Nijmegen, Nijmegen, the Netherlands.

This work was facilitated by a J. F. Schouten Institute for User System Interaction grant and a Royal Netherlands Academy of Arts and Sciences fellowship.

We thank John Bargh, Peter Gollwitzer, Sander Koole, Rene Lion, Edwin Poppe, Peep Stalmeier, and Marcel Zeelenberg for their helpful comments on earlier versions of this article. We are grateful to Ankie Bosch, Erica Derijcke, Peter De Vries, Alderina Fokkema, Christel Van Vught, and Ronald Willemsen for their help in collecting the data.

Correspondence concerning this article should be addressed to Henk Aarts, Department of Psychology and Language, DG 0.23, Eindhoven University of Technology, P.O. Box 513, 5600 MB Eindhoven, the Netherlands. Electronic mail may be sent to h.a.g.aarts@tm.tue.nl. portant contribution in this field was made by Bentler and Speckart (1979), who investigated students' consumption of alcohol and marijuana. These authors suggested that such actions become habitual over time and, importantly, that they can be instigated without mediation of attitudes or intentions (or "products of reasoning" in general). Indeed, the results of their study clearly showed that a measure of habit (obtained by self-reported frequency of behavior in the previous 2 weeks) does predict future behavior directly, indicating that such behavior is initiated automatically, that is, without deliberation and thought.

The work of Bentler and Speckart (1979) has been replicated by many other investigators in a wide variety of behavioral domains. Ouellette and Wood's (1998) meta-analysis of studies on habits showed that the direct influence of past behavior on future behavior was most pronounced for behaviors executed frequently and consistently in a stable context. Behaviors carried out less often were more accurately predicted by consciously formed intentions toward the behavior. This pattern of results indeed confirms the assumption that when a behavior has been performed many times in the past, future behavior becomes increasingly under control of an automatized process, whereas a behavior executed less frequently is (still) guided by evaluative interpretations and considerations (as expressed, for instance, in the theory of reasoned action; Fishbein \& Ajzen, 1975). In summary, there is ample evidence indicating that habitual behavior (with habitual defined as a function of relative frequency of past performance) is automatic. It is determined by past behavior and not mediated by attitudes, intentions, or other concepts referring to more deliberate or conscious processes (see also Aarts, Verplanken, \& van Knippenberg, 1998; Triandis, 1980).

The direct influence of past behavior performed frequently on future behavior also underscores the behaviorists' maxim that behavior is largely influenced by habit (e.g., Hull, 1943; Skinner, 1938; Watson, 1914). Actually, the direct relation between past and future action shows that people simply do things as they did them before. Because the concept of habit is strongly rooted in behaviorist approaches to learning theory, it was assumed for a 
long time that mental (or cognitive) processes do not mediate the automatic activation of habitual responses to environmental stimuli. In contemporary research, however, it is often argued that cognition does play a role in the direct control of environmental cues over behavior (e.g., Bargh \& Chartrand, 1999; Bargh \& Gollwitzer, 1994; Norman \& Shallice, 1986; Ronis, Yates, \& Kirscht, 1989). In line with this research, our main hypothesis is that habits are mentally represented and that they can be activated automatically.

Specifically, we conceive of habits as a form of goal-directed automatic behavior (cf. goal-dependent automaticity; Bargh, 1989). Habits are represented as links between a goal and actions that are instrumental in attaining this goal. The strength of such links is dependent on frequent co-activation of the goal and the relevant actions in the past. The more often the activation of a goal leads to the performance of the same action under the same circumstances, the stronger the habit (i.e., the link between goal and action) will become. Our purpose was to investigate some key assumptions derived from this conceptualization. First, we hypothesized that habitual behavior can be activated automatically. Second, we assumed that this automatic activation does not occur for behavior that is not habitual (not represented as a goal-action link). Third, we assumed that the automatic activation of a habitual action is goal dependent. That is, actions are automatically activated provided that the relevant goal is activated in the first place.

\section{Development and Representation of Habits}

Goals refer to desired, or anticipated, outcomes or end states (Austin \& Vancouver, 1996; Gollwitzer \& Moskowitz, 1996; Locke \& Latham, 1990). These goals can be the consequence of physiological needs, such as thirst and hunger, as well as various other "needs" or motives, such as restoring personal hygiene, making friends, acquiring knowledge, or becoming a professor (e.g., Geen, 1995; Mook, 1996). When goals are not pursued often, actions that one can deploy to attain desired outcomes are not specified in these goals. Instead, goal activation guides organisms to select an action or to form a plan to perform a certain action (see also Carver \& Scheier, 1981; Cohen, 1996; Srull \& Wyer, 1986), but it does not lead to the immediate instigation of an action. Hence, when pursuing relatively unfamiliar goals, people are likely to ponder the possible actions they can use to achieve the goal before they engage in an action. ${ }^{1}$

When goals are pursued regularly, however, the need to pay conscious attention to details dwindles (e.g., Anderson, 1982; Fitts \& Posner, 1967; Newell \& Rosenbloom, 1981). When people select the same actions more often and when these actions lead to goal achievement in a satisfactory manner, the actions become mentally linked to the goal. That is, selecting and performing the same goal-directed behavior frequently and consistently leads to associations between the goal and the instrumental actions (i.e., to the formation of a habit). As a result, activation of these goals spreads automatically to the associated actions (cf. Anderson, 1993; Mäntylä, 1993). The exhibition of habits, then, is the result of the automatic and immediate activation of the habitual action on the instigation of a goal.

These goals are critical. In the case of habits, the instigation of the goal to act is necessary to activate the associated actions automatically. Many well-practiced or skilled actions, such as typing, driving a car, and riding a bicycle, are usually qualified as automatic or habitual, but they require the activation of a goal. For instance, an undergraduate student needs a goal to use a bicycle (e.g., traveling to attend lectures at the university) to activate subsequent behavioral steps such as "going to the garage to get the bike" and "turning left at the statue of the hairy dromedary." In a sense, habits can be seen as hierarchical mental representations in which activation of a goal leads to activation of a number of associated behaviors lower in the hierarchy. The proposal of such a hierarchical structure of action is consistent with others who have previously proposed such a representation (Carver \& Scheier, 1981; Gallistel, 1985; Miller, Galanter, \& Pribram, 1960; Mischel, 1973; Powers, 1973; Vallacher \& Wegner, 1987; see also Schank \& Abelson, 1977).

It should be noted that our perspective on the development of (the cognitive representation of) habits is also partly based on the recent work of Bargh (1990; see also Bargh \& Gollwitzer, 1994). He has suggested that when the same choices are frequently pursued and implemented in a given situation (or as the result of a given goal), an association between the mental representation of that situation and the representation of the goal-directed action will emerge. Frequent coactivation of a particular situation and a particular behavioral decision increases the strength and accessibility of that association. Hence, frequent and consistent performance of a goal-directed action in a specific situation facilitates the ease of activating the mental representation of this behavior (and hence the resulting action itself) by the situation. Similar principles have also been proposed and empirically established for the activation of other mental representations, such as attitudes and stereotypes (Devine, 1989; Fazio, Sanbonmatsu, Powell, \& Kardes, 1986; for an overview, see Higgins, 1996).

\section{Activation of Goal-Directed Action}

That the environment is indeed capable of activating goaldirected behavior automatically has been established in the domain of motivations. In a test of their automotive model, Bargh and colleagues (Bargh, 1997; Bargh, Gollwitzer, Chai, \& Barndollar, 1999) showed that goals (and the associated actions) can be elicited directly by the environment. Activation in this case occurs without the person's awareness. They found that participants who were primed with achievement or affiliation goals behaved in accordance with the primed goal (solving either many or a few word puzzles in the presence of a confederate who appeared to be not skilled in the task). In other words, the situation elicited the relevant behavior as dictated by the primed goal.

Support for the idea that the activation of actions depends on the underlying mental representation and that this representation differs as a function of one's personal history was obtained by Bargh,

\footnotetext{
${ }^{1}$ In current research on the goal concept, different dimensions are postulated on which goals may vary, such as level of abstraction, difficulty, complexity, and temporal range (e.g., Austin \& Vancouver, 1996; Gollwitzer \& Moskowitz, 1996). Of course, these goal dimensions are not necessarily orthogonal. For the sake of argument, however, the focus here is on the functionality of relatively short-term goals. For example, an undergraduate's wish to travel to the university to attend lectures can be seen as a short-term goal, one that may be functional in achieving a long-term goal (e.g., earning money or becoming a professor).
} 
Raymond, Pryor, and Strack (1995). They established that power (as a situational feature) and sexuality are mentally associated, but only for those with sexual harassment tendencies. Hence, this research shows not only that the environment can have a direct impact on goal-directed behavior but also that this effect is dependent on whether goal and action are associated: The environment affects goal-directed behavior automatically only if goals are associated with the environment (i.e., when this goal was pursued earlier in the same situations). Our conceptualization of habit is comparable with this perspective. The environment can activate goal-directed behavior automatically, but only when this behavior is habitual, that is, only when the behavior is associated with the activated goal.

In summary, this evidence supports the idea that goal-directed behavior is mentally represented and can be automatic. As we have argued, our conceptualization of habits is based on these ideas. We conceive of habits as a form of goal-directed automatic behavior. Habits are represented as associations between goals and actions that allow the instigation of automatic behavior on the activation of these goals by the environment. The degree of "habitualness" of behavior is argued to be a consequence of the frequency with which these goal-directed actions have been performed in similar situations in the past.

In the present article, we report three experiments that were designed to test the key assumptions about habits formulated earlier. In these experiments, we studied cycling behavior among Dutch college students as an example of habitual behavior. Our main purpose was to investigate whether, and under what circumstances, bicycle use is capable of being directly activated by travel goals such as "going to attend lectures at the university" and "going shopping at the city center mall."

\section{Experiment 1}

In the first experiment, we tested the hypothesis pertaining to the key assumption that habits can be seen as mental associations between travel goals and (transportation) action and, hence, that these goals can activate habitual transport behavior automatically. That is, we hypothesized that habitual action is activated automatically on the instigation of a goal and that such actions are not activated among people for which the behavior is not habitual. A secondary aim was to show that goals can exert their influence on habitual responses when people are not aware of the relation between an earlier-primed goal and the habitual response.

In this experiment, habitual and nonhabitual bicycle users were primed or not primed with travel goals (e.g., having to attend lectures) and then asked to respond to the word bicycle after being presented with locations (e.g., university) that corresponded to the earlier-activated travel goal. Response latencies on the locationbicycle links served as the dependent variable. We assumed that habitual bicycle users would show enhanced accessibility and thus respond faster to the word bicycle than nonhabitual bicycle users but only after being activated with the goal to travel. We did not expect habitual and nonhabitual bicycle users to differ in their speed of responding when the goal to travel was not activated.

\section{Method}

Participants and design. Fifty-four students at the University of Eindhoven participated in the experiment, receiving 5 Dutch guilders (approx- imately \$3) in return. Because the experiment focused on bicycle use for short trips, only university students were recruited who lived in or around Eindhoven and who owned a bicycle. However, these participants varied in the frequency with which they used their bicycles, which is crucial for obtaining different levels of bicycle habit strength (i.e., nonhabitual vs. habitual). Participants were randomly assigned to one of the two experimental conditions: a goal priming condition and a no goal priming control condition.

Selection of materials. Initially, a pilot study was conducted to obtain travel goals and corresponding locations for which bicycle use constituted a realistic transport mode option for all participants. Forty-two University of Eindhoven students were presented with 60 different locations inside and outside the city and were asked to assess the usefulness of four travel modes (bicycle, bus, walking, and train) to these locations. We obtained 5 locations (e.g., a shopping area, called "heuvelgalerie," a sports center, and a popular night-life area, called "stratumseind") for which a bicycle constituted a realistic option for all students (percentages mentioning use of a bicycle for travel to these destinations were nearly all $100 \%$ ). Thus, these locations represent travel destinations for which a bicycle is a realistic travel mode. We subsequently asked the students to mention the main reason to travel to each of the 5 locations. For each location, we selected the most frequently mentioned reason, which provided us with descriptions of five travel goals (e.g., shopping at the city center mall). These five travel goals and corresponding travel destination-bicycle pairs composed the targets of interest in Experiment 1 (as well as in the subsequent experiments). In addition, 5 locations were obtained involving trips for which a bicycle did not represent an option (e.g., Maastricht, a city approximately $90 \mathrm{~km}$ from Eindhoven). Furthermore, for each of the other three travel modes (walking, bus, and train), $S$ location-option combinations and 5 lacation-no option combinations were obtained. The latter 35 location-travel mode units (i.e., all except the first 5) served as filler trials in the association task (described later).

Experimental task and procedure. Participants worked in separate cubicles. Computers were used to run the experiments and the computer program provided all instructions. As a cover story, participants were told that they would take part in a study conducted by the Department of Psychology and Language. Moreover, they were told that the study consisted of three separate tasks designed by different department research teams. In reality, the first task served as the manipulation phase for goal priming, and the second task was designed to study the effects of habit and goal priming on the speed of responding to the target bicycle trips. Habit strength was assessed in the third task.

In the first task, announced as the "media and information use inventory task," we were allegedly interested in several aspects of communication and language (e.g., participants were asked to estimate how many hours a week they watch television, whether they make use of video text, and so on). As part of this task, half of the participants learned that they had to read five different sentences that designated students' activities in daily life (goal priming condition). Participants were told that we were interested in how long it takes individuals to read each sentence. This information was allegedly helpful for the purpose of designing new communication systems. Participants were instructed to press a button after they had carefully read the sentence. The five sentences actually described the five different travel goals (e.g., going shopping at the city center mall) that corresponded to the five travel locations (e.g., heuvelgalerie) obtained in the pilot study and used later in the travel mode association task. It is important to note that we did not provide the travel locations per se; rather, we provided only the reason to go to each location (e.g., going shopping). Each description thus consisted of one short sentence representing a goal to travel to a destination with a certain transport mode. The sentences were presented in random order in the center of the computer screen. The other half of the participants (those in the control condition) did not read these sentences as 
part of the inventory task and thus started with the second task without being exposed to (or primed with) the travel goals. ${ }^{2}$

The second task was announced as an association task allegedly designed to study relations between all sorts of locations and travel behavior. Participants were told that 40 different location words would appear briefly on the screen followed by a mode of transport. Their task was to indicate, as quickly and as accurately as possible, whether the presented mode would constitute a realistic means of transport for the previously presented location. Furthermore, they were told that 200 different locations were stored in the memory of the computer and that the computer would first randomly select the 40 locations. An hourglass was displayed on the computer screen, simulating the selection procedure. By using this (fake) selection procedure, we hoped to further reduce any perceived connection between the goal priming task and the association task. The 40 location-transport mode trials were presented in random order and preceded by eight practice trials. Thus, the five target location-bicycle trials were embedded in the filler trials. This relatively large number of fillers was incorporated to create a genuine multiple response situation, that is, to ensure that participants had to respond to different locations with different travel modes.

An experimental trial consisted of the following sequence of events: (a) presentation of a row of asterisks (i.e., fixation point) for $500 \mathrm{~ms}$, (b) presentation of the location word for $200 \mathrm{~ms}$, (c) presentation of a row of asterisks (i.e., postmask) for $100 \mathrm{~ms}$, and (d) presentation of a travel mode. Thus, the stimulus onset asynchrony (SOA; i.e., the time between presentation of the location and the travel mode) was set at $300 \mathrm{~ms}$. This time interval was assumed to be too short to allow participants to form expectancies and to implement strategic processes, and hence we measured automatic responses this way (cf. Neely, 1991). The travel mode word remained on the screen until the participant responded. Everything appeared at the same location on the screen. Responses were collected from the PC's keyboard. Participants pressed a key labeled yes or no. To obtain maximum speed during the task, participants were instructed to keep their fingers above the keys throughout the task. Response latencies were measured from the onset of the travel mode, but participants had to respond within $3 \mathrm{~s}$. If participants completed a trial within the allotted time, the message "pay attention" was presented for $2 \mathrm{~s}$ on the screen, indicating that the computer would initiate the next trial. However, if no response was given after $3 \mathrm{~s}$, the message "please, respond faster" was presented, followed by the announcement of the next trial. The dependent variable was the response latency across the five target location-bicycle pairs.

With the third task, introduced as the leisure time inventory, we measured habit strength. Participants' estimates of frequency of bicycle use in the recent past for different trips were used to obtain information on their bicycle habit strength. This operationalization coincided with Hull's (1943) early work on habit formation in which he proposed that, as the number of repeated pairings between a situation (e.g., travel location) and a response (e.g., travel mode) increases, so does the strength of that association or habit. Specifically, participants were presented with a sample of 10 travel Jocations; for each location, they were asked to count the number of times they had traveled there with their bike in the previous 2 weeks. The presented locations consisted of the five target destinations and five other locations situated near the target locations. Next, we averaged the frequency estimates of bicycle use across the 10 destinations and, on the basis of a median split, categorized participants as nonhabitual or habitual in regard to bicycle use. Because this measurement procedure could serve as a prime for locations and bicycle, we decided to measure habit strength at the end of the experimental session, that is, after the goal priming and association tasks (see Bargh \& Chartrand, 1999, on the subject of unwanted effects of priming). Furthermore, as a means of attenuating possible influences of the previous tasks on the estimates, participants were explicitly instructed to be as accurate as possible in their recall (Aarts \& Dijksterhuis, 1999; cf. Thompson, Roman, Moskowitz, Chaiken, \& Bargh, 1994).

After the measurement of habit strength, participants were thoroughly debriefed. The debriefing indicated that participants were unaware of the
Table 1

Mean Response Latencies (in ms) as a Function of Habit Strength and Goal Prime: Experiment 1

\begin{tabular}{lll}
\hline & \multicolumn{2}{c}{ Goal prime } \\
\cline { 2 - 3 } Habit strength & No & Yes \\
\hline Nonhabitual & 863 & 958 \\
Habitual & 883 & 759 \\
\hline
\end{tabular}

hypotheses under investigation. Moreover, they did not perceive a link between the two tasks and, therefore, perceived no connections between the travel locations used in the goal priming and association tasks. Therefore, we could conclude that we succeeded in creating two ostensibly unrelated tasks.

\section{Results and Discussion}

All participants completed the five target trials within the allotted time. Only latencies concerning yes responses across the five location-bicycle pairs were included in the analyses $(99.3 \%$ of all responses, a percentage that might be expected on the basis of our pilot study). We computed the average response latency across the five target location-bicycle trials for each participant. Response latencies were subjected to a 2 (goal priming: present vs. absent) $\times 2$ (habit strength: nonhabitual vs. habitual) betweensubjects analysis of variance (ANOVA). The means for each cell in the design are displayed in Table 1.

As Table 1 shows, habitual participants' responses were slightly faster than nonhabitual participants' responses, $F(1,50)=3.89$, $p<.06$. The main effect of goal priming was nonsignificant, $F(1$, $50)=0.10$. More important, however, the ANOVA revealed the predicted two-way interaction of habit strength and goal priming, $F(1,50)=5.87, p<.02$. Planned comparisons showed that, in the no goal prime condition, habitual participants' response latencies did not differ reliably from nonhabitual participants' response latencies, $F(1,50)=0.11, n s$. However, habitual participants' response latencies were significantly faster than responses of nonhabitual participants in the goal priming condition, $F(1$, $50)=9.21, p<.005$. Planned comparisons between the no goal prime and goal prime conditions yielded no reliable effect in the nonhabitual group, $F(1,50)=2.30, n s$, and a marginally significant effect in the habitual group, $F(1,50)=3.22, p<.08$. This second effect shows that habitual participants reponded faster after being primed with travel goals.

The results of Experiment 1 supported our predictions. Habitual bicycle users who were primed with travel goals showed faster responses than nonhabitual bicycle users. Furthermore, this effect did not appear in the absence of goal priming. As hypothesized, the data show that activation of travel goals is required to reveal the mental accessibility of the habitual travel behavior. In general

\footnotetext{
${ }^{2}$ One may remark that the goal priming condition and the control condition differ on more aspects than simply goal priming (e.g., some people did spend more time in the laboratory than others). However, such differences can have an impact on the main effect of goal priming but not the hypothesized, and critical, two-way interaction of habit strength and goal priming.
} 
terms, the automaticity of habitual behaviors is conditional on the presence of a goal (cf. goal-dependent automaticity; Bargh, 1989).

\section{Experiment 2}

The main goal of Experiment 2 was to compare habits with conscious planning. We have argued that habits are represented as links between goals and actions instrumental in attaining these goals and that these links are the result of frequent coactivation of goal and action. However, there is another way in which strong links between goals and actions are established, namely through the formation of implementation intentions (Gollwitzer, 1993, 1996). These intentions take the form of "I will do $x$ whenever situation $z$ occurs," and hence they link an action to a goal. Such intentions are strategically formed by individuals to promote the initiation of goal-directed action, especially when the performance of the action has to be postponed and alternative actions can interfere. For instance, a person intending to drive an alternative route when going home from work (a nonhabitual goal-directed action that is often insufficiently implemented) may increase the chances of indeed driving this route by planning.

Our hypothesis is that habits can be simulated by implementation intentions but that habitual behavior does not profit from planning (for a similar line of reasoning, see Bargh \& Gollwitzer, 1994). This idea stems from the assumption that strategic planning leads to essentially the same goal-action links (e.g., "I will use the bicycle when having to attend lectures at the university") as the ones we assume to represent habits. These intentionally formed associations between goal and action are functionally equivalent to habitual associations, and hence such actions may be automatically activated as well (Gollwitzer, 1993). The only difference is that habits are the result of frequent past behavior, whereas links stemming from implementation intentions are the result of conscious (recent) planning. However, and this is important, because habits are already backed by strong links between goals and action, it is anticipated that only nonhabitual individuals may benefit from planning in the sense of enhanced accessibility or faster responses to a travel mode after goal priming. Habitual people, on the other hand, already possess these strong links and are expected not to benefit from planning. Thus, by comparing habits and planning, we may be able to show similarities between more chronic (habitual) and temporary primed forms of automatized actions (Bargh, Bond, Lombardi, \& Tota, 1986; Fazio et al., 1986; Srull \& Wyer, 1986).

To test these ideas, we examined the interaction between bicycle habit strength and the formation of implementation intentions (by means of planning travel goals) using the same association task as in Experiment 1. All participants were given the same five travel goals. However, two different planning procedures were designed. Participants in the experimental condition planned to use the bicycle for travel goals, whereas participants in the control condition were required to plan a different action, namely to repair a flat tire of a bicycle. This was done to ensure that we did not make the term bicycle more accessible for one group than for the other.

Experiment 2 served two further purposes. First, we tried to replicate the effect of habit on associative strength between goals and actions under conditions of goal activation by manipulating goals in a different manner. In this experiment, participants learned that they actually had to travel on finishing the experiment. Sec- ond, we included mediator variables to rule out alternative explanations for the observed effects of habit and planning. For instance, the two planning conditions could yield differences in strength of travel goal activation or perceived feasibility of using a bicycle. As a result, the effect of planning on response times could be attributable to variances in these variables. Also, it can still be argued that the effects of bicycle habit are guided by evaluative rather than goal-directed automatic processes and, thus, may be mediated by perceived desirability of (or attitudes toward) bicycle use. For the present purpase, three potential mediators seemed relevant to test for mediator effects: strength of travel goal instigation, perceived feasibility of bicycle use, and desirability of bicycle use.

\section{Method}

Participants and design. University students were recruited who lived in or around the city of Eindhoven and who owned a bicycle. Fifty-three undergraduates were randomly assigned to one of the two experimental conditions: a related planning condition and an unrelated planning condition (control). Habit strength (nonhabitual vs. habitual) was measured. Participants received 5 Dutch guilders (approximately $\$ 3$ ) in return for taking part.

Experimental task and procedure. Participants were told that they would take part in research conducted by the Department of Psychology and Language and that three separate tasks designed by different research teams had to be performed. The experiment was run on computers. The computer program provided all instructions. Participants worked in separate cubicles and were provided with three consecutive tasks: a planning task, an association task, and the habit measure.

In the first task, participants learned that the study involved the relation between language and planning in daily life and that they would be requested to plan the steps required to perform a certain task. Initially, all participants were told that one of five different travel goals should be personally attained by use of a bicycle after the experiment and that they had to report on their experiences of the attained goal. Subsequently, they were instructed to read the descriptions of five travel goals (see Experiment 1). Participants learned that the decision as to which of the goals they had to attain would be revealed to them after the experimental session. Furthermore, to stress the importance of the task, we informed participants that the study was designed to test whether the language used in the planning task is affected when individuals do not know in advance which goal they have to attain. At this point, the instructions for the two conditions began to differ.

Half of the participants were then told to imagine having a flat tire that had to be repaired. These participants were asked to plan the subgoals required to repair the flat tire. This condition was referred to as the unrelated planning condition and could be treated as a control condition, because participants were requested to plan activities not directly related to the attainment of the travel goals. They were handed a booklet containing separate sheets listing five major subgoals of repairing a flat tire (e.g., searching for the repair kit and looking for a spot to fix the flat tire). This was done to keep the working load and procedure similar to the related planning condition (as described subsequently). Moreover, as a means of ensuring that participants perceived the task as realistic, they were told that the five subgoals emerged from the planning activities of students in a previous study. For each subgoal, participants were requested to write down when (time of the day), where (locating the spot to attain the subgoal), and how (procedure) they would accomplish it.

In the experimental condition (referred to as the related planning condition), participants were asked to plan the five travel goals. They were also provided with a booklet, but this time the booklet contained the assignment to plan the three steps of the five travel goals on separate sheets. For each 
travel goal, participants were requested to write down when (time of the day), where (locating the district of the destination, e.g., in the city center), and how (the route of travel) they would accomplish it. It should be noted that we asked participants to write down the district and not the location itself. All participants were given $6 \mathrm{~min}$ to complete the planning task.

After the planning task, as part of a larger questionnaire, participants responded to the following three questions:

1. How likely do you believe it is that you will use the bicycle for one of the five travel goals?

2. To what extent do you believe that, on average, the bicycle is a feasible mode to use for the five travel goals?

3. To what extent do you believe that, on average, the bicycle is a desirable mode to use for the five travel goals?

The first item served as a check of the strength of the travel goals, and the last two items captured the perceived feasibility of and desirability of (attitude toward) using the bicycle for the five travel goals. All items were accompanied by unipolar 9-point response scales ranging from not at all (I) to very much (9).

After completion of the planning task and questionnaire, participants leamed the same association task as in Experiment 1. Moreover, we used the same cover story and the same fake selection procedure as in Experiment 1 to further minimize the perceived connection between the target locations used in the planning and association tasks. The dependent variable was the response latency across the five target location-bicycle pairs.

After completing the association task, participants reported their frequency estimates of bicycle use across 10 travel destinations (see Experiment 1). On the basis of a median split, they were categorized as nonhabitual or habitual in regard to bicycle use.

Debriefing indicated that participants had no idea about the true nature of the experiment. First, all participants were unaware of the hypotheses under investigation. Furthermore, although most participants expressed a belief that the tasks were dealing with the same subject (i.e., the tasks focused on travel behavior), none of them had actually noticed that some of the locations in the association task were related to the travel goals in the planning procedure. In summary, none of the participants indicated suspicion as to the actual relation between the tasks. Not surprisingly, some participants spontaneously asked which trip they were supposed to make, revealing that we succeeded in the instigation of actual travel goals. Of course, we informed all participants that the travel goals were provided only to test our hypotheses, but we added that they were free in making whatever trip they wanted to make.

\section{Results and Discussion}

All participants completed the five target trials within the allotted time. Only latencies concerning yes responses across the five location-bicycle pairs were included in the analyses $(99.25 \%$ of all responses). We computed the average response latency across the five target bike-location trials for each participant. Response latencies were subjected to a 2 (planning: unrelated vs. related) $\times 2$ (habit strength: nonhabitual vs. habitual) betweensubjects ANOVA. The means for each cell in the design are displayed in Table 2 .

As can be seen in Table 2, habitual participants' responses were faster than nonhabitual participants' responses, $F(1,49)=4.66$, $p<.04$, thereby replicating the effect of habit strength on response latency in the goal activation condition of Experiment 1. The main effect of planning was also highly significant, $F(1,49)=9.04, p<$ .005. Participants' response latencies in the related planning condition were faster than participants' responses in the unrelated planning condition. More important, the ANOVA revealed the predicted two-way interaction of habit strength and planning, $F(1$, $49)=5.56, p<.03$. Planned comparisons revealed that habitual
Table 2

Mean Response Latencies (in ms) as a Function of Habit Strength and Type of Planning: Experiment 2

\begin{tabular}{lcc}
\hline & \multicolumn{2}{c}{ Type of planning } \\
\cline { 2 - 3 } Habit strength & Unrelated & Related \\
\hline Nonhabitual & 1,153 & 869 \\
Habitual & 914 & 880 \\
\hline
\end{tabular}

participants' response latencies were not affected by type of planning, $F(1,49)=0.02$, ns. However, nonhabitual participants' response latencies were significantly faster in the related planning condition than in the unrelated planning condition, $F(1,49)$ $=13.95, p<.003$. These latter results show that planning (or formation of implementation intention) facilitated the speed of nonhabitual participants' responses, whereas this was not the case for habitual participants.

Potential mediators of the observed effects. Three variables were measured after completion of the planning task. With these measures, we wanted to rule out potential mediators. Specifically, we measured strength of goal activation and perceived feasibility and desirability of bicycle use. We first examined whether there were any significant effects of planning and habit on the three mediators, and we subsequently performed a 2 (planning: unrelated vs. related) $\times 2$ (bicycle choice habit strength: nonhabitual vs. habitual) between-subjects analysis of covariance (ANCOVA) with the potential mediators as covariates.

Strength of travel goal activation. Participants in all conditions believed to the same extent that they had to use the bicycle for one of the five travel goals $(M=7.55, S D=1.88)$. Nonhabitual participants did not differ significantly from habitual participants, $F<1$, and participants in the unrelated planning condition did not differ from participants in the related planning condition, $F<1$. The interaction of habit strength and planning was also nonsignificant, $F<1.52$. Note that the mean was well above the midpoint of the 9-point scale, suggesting that, on average, participants took the manipulation of goal instigation seriously.

Perceived feasibility of bicycle use. There were no differences between conditions with respect to participants' conviction that the bicycle was a feasible option to use for the travel goals $(M=8.36$, $S D=0.86$ ), as indicated by nonsignificant effects of habit strength, planning, and their interaction (all $F \mathrm{~s}<1$ ).

Perceived desirability of bicycle use. Participants in the different conditions judged the bicycle equally desirable $(M=7.42$, $S D=1.67$ ). The main effects of habit strength and planning and their interaction were nonsignificant (all $F \mathrm{~s}<1$ ).

An ANCOVA with the three mediator variables as covariates yielded the same pattern of significant results for habit, planning, and their interaction: $F(1 ; 46)=5.54, p<.03 ; F(1,46)=9.63$, $p<.005$; and $F(1,46)=5.52, p<.03$, respectively (these effects were much the same as the ones resulting from the original ANOVA's). Taken together, then, these analyses indicate that the observed pattern of results is attributable neither to the "magnitude" of goal activation nor to the perceived feasibility and perceived desirability of using the bicycle as a mode of transport for the five travel goals. 
The first conclusion to be drawn is that, in Experiment 2, we replicated the results of Experiment 1. After activation of a travel goal, habitual bicycle users responded faster to bicycle trips than nonhabitual bicycle users. Moreover, we obtained a reliable effect of planning. When travel goals were furnished with related implementation intentions, participants responded much faster than those who formed unrelated implementation intentions. The latter group was much slower in linking the bicycle to the travel destinations. As hypothesized, this effect was present only among nonhabitual bicycle users. Habitual bicycle users did not benefit from planning, which supports the idea that these participants already possessed strong associations between travel goals and transport behavior. The observed effects were not mediated by judgmental or strategic processes, as indicated by the mediator analyses.

Together, the results of Experiments 1 and 2 suggest that habits are mentally represented as associations between goals and actions. In addition, we demonstrated that the links between goal and action can be simulated, namely when the transport behavior is linked (by planning) to the travel goal.

\section{Experiment 3}

It should be noted that, in Experiments 1 and 2, the strength of the goal-action link was assessed with a task in which participants were requested to associate a transport mode option with a briefly presented travel location that corresponded to the earlier-activated travel goal. However, although we assume that the inclusion of locations does not influence the hypothesized process, the purpose of Experiment 3 was to replicate the major finding of Experiments 1 and 2 by experimentally manipulating the presence versus absence of the locations words. Specifically, we sought to test whether the speed of responding to bicycle use is enhanced as a function of the locations. Our conceptualization entails that these locations are irrelevant and that it is the activated goal that is responsible for the habitual response. However, one may argue that the presented locations themselves can enhance the accessibility of the habitual response. Experiment 3 was designed to rule out this possibility.

To assess the influence of the presence versus absence of location words, we used a procedure largely similar to the sequential priming paradigm (Fazio et al., 1986; Neely, 1977). In the present procedure, participants were briefly presented with a prime word and required to indicate whether a subsequent word was a verb or not. In other words, we wanted participants to produce a response of the form "word $x$ is an action" after being briefly presented with another word. Among these prime words, we included the five location words as well as five neutral words. All of these words were immediately followed by the word cycling (SOA: $300 \mathrm{~ms}$ ). Goal activation was experimentally manipulated, and habit strength was measured by self-reported frequency of past bicycle use. If the results of Experiments 1 and 2 are not the product of the presence of location words, as we hypothesize, habitual bicycle users should respond faster to the word cycling than nonhabitual bicycle users, irrespective of whether it was preceded by a location (but, of course, dependent on goal priming). Hence, we predicted an interaction between habit strength and goal activation. Conversely, if presentation of location words does affect the responses, a three-way interaction effect among goal activation, habit strength, and the presence versus absence of location words should emerge.

\section{Method}

Participants and design. University students were recruited who lived in or around the city of Eindhoven and who owned a bicycle. Eighty-nine undergraduates participated in the experiment, receiving 7.5 Dutch guilders (approximately $\$ 4.50$ ) in return. They were randomly assigned to experimental conditions. Habit strength (nonhabitual vs. habitual) was measured.

Experimental task and procedure. Participants were informed that they would take part in research conducted by the Department of Psychology and Language and that three separate tasks designed by different research teams had to be performed. The experiment was run on computers. The computer program provided all instructions. Participants worked in separate cubicles and were provided with three consecutive tasks: a goal activation task, a verb verification task, and the habit measure.

As part of the introduction to the experimental session, participants learned that one part of the study involved actual performance of behavior and that they would be requested to perform a certain task. Specifically, participants were told that one of five tasks should be executed at home after the experiment and that they had to report on their experiences later. Participants learned that the task they had to perform would be announced after the experimental session. Subsequently, they were instructed to carefully read the descriptions of the five respective tasks and to press a button after they had read each description. The descriptions were presented in random order in the center of the computer screen. Half of the participants received five tasks unrelated to travel behavior (e.g., making a telephone call or watching a movie on TV). This condition, labeled the unrelated goal condition, could be treated as a control condition. In the experimental condition (referred to as the related goal condition), participants were exposed to the five travel goals used in the previous two experiments.

After activation of the goal, participants were confronted with the verb verification task, allegedly designed to study people's capacity to detect different types of words. Participants were informed that there would be two words presented one after the other on the screen and that they were to press the yes or no button to indicate, as quickly and accurately as possible, whether the second word was a verb or not. For the sake of clarity, participants were told that the verbs designated mundane activities people perform and that the nonverbs designated mundane objects. No explanation or instructions were given regarding the prime words (cf. Bargh, Chaiken, Govender, \& Pratto, 1992).

An experimental trial consisted of the following sequence of events: (a) presentation of a row of asterisks (i.e., fixation point) for $500 \mathrm{~ms}$, (b) presentation of the prime word for $200 \mathrm{~ms}$, (c) presentation of a row of asterisks (i.e., postmask) for $100 \mathrm{~ms}$, and (d) presentation of a (second) target word. The second word remained on the screen until the participant responded. Everything appeared at the same location on the screen. Responses were collected from the PC's keyboard. Participants pressed a key marked yes or no. To obtain maximum speed during the task, participants were instructed to keep their fingers above the keys throughout the task. Response latencies were measured in milliseconds from the onset of the second word to the time participants pressed a button. The interval between word trials was $2 \mathrm{~s}$.

Participants were required to respond to two blocks of 80 word pairs. In each block, 40 of the target words were verbs, and 40 were not verbs. Among the 40 verbs, we presented the verb cycling five times. In one block (Block 1), the verb cycling was preceded by location words. In the other block (Block 2), cycling was preceded by words not designating a location. Thus, the word trials were identical for the two blocks with the exception that, in one block, cycling was preceded by location primes (locationcycling pairs), whereas this was not the case in the other block (no location-cycling pairs). In each block, the other word pairs served as fillers. Within blocks, the word trials were presented in random order and preceded by eight practice trials. As a means of controlling for order 
effects, participants were randomly assigned to one of the two order conditions: Block 1-2 versus Block 2-1. Participants were allowed to rest for $30 \mathrm{~s}$ between blocks. The dependent variable was response latency across the five cycling trials.

After completion of the verb verification task, participants reported their frequency estimates of bicycle use across 10 travel destinations. On the basis of a median split, they were categorized as nonhabitual or habitual in regard to bicycle use.

Debriefing indicated that participants had no idea about the true nature of the experiment. First, all participants were unaware of the hypotheses under investigation. Second, none of the participants indicated suspicion as to the actual relation between the tasks.

\section{Results and Discussion}

Only latencies concerning yes responses across the cycling trials were included in the analyses (98\% of all responses). We computed the average latency across the five neutral word-cycling trials and the five location-cycling trials for each participant. Response latencies were subjected to a 2 (goal activation: unrelated vs. related) $\times 2$ (habit strength: nonhabitual vs. habitual) $\times 2$ (location prime: absent vs. present) ANOVA. Goal activation and habit strength were between-subjects variables.

The ANOVA revealed that habitual bicycle users responded slightly faster to cycling than the nonhabitual users, although this effect failed to reach significance, $F(1,85)=1.57$, ns. However, the expected interaction between goal activation and habit strength was significant, $F(1,85)=5.35, p<.03$. No other effects were reliable (including the three-way interaction among goal activation, habit strength, and location prime, $F<1$ ). Table 3 shows the Goal Activation $\times$ Habit Strength effect on latencies, with the means collapsed across the two types of prime words.

To explore the nature of the Goal Activation $\times$ Habit Strength interaction, we conducted planned comparison tests. These tests showed that, in the unrelated goal activation condition, habitual participants' response latencies did not differ reliably from nonhabitual participants' response latencies, $F(1,85)=0.58$, ns. However, habitual participants' response latencies were significantly faster than responses of nonhabitual participants in the related goal activation condition, $F(1,85)=6.34, p<.02$. Comparisons between the unrelated and related goal activation conditions yielded no reliable effect in the nonhabitual group, $F(1$, $85)=1.95, n s$, and a marginally significant effect in the habitual group, $F(1,85)=3.58, p<.07$.

In summary, the results of Experiment 3 indicate that the automatic activation of a habitual response is conditional on the presence of a travel goal, thereby replicating the results of the previous experiments. This interaction effect emerged regardless of whether travel locations were presented or not presented, suggesting that

Table 3

Mean Response Latencies (in ms) as a Function of Habit Strength and Goal Activation: Experiment 3

\begin{tabular}{lcc}
\hline & \multicolumn{2}{c}{ Goal activation } \\
\cline { 2 - 3 } Habit strength & Unrelated & Related \\
\hline Nonhabitual & 695 & 734 \\
Habitual & 717 & 659 \\
\hline
\end{tabular}

the locations did not influence the observed pattern of results. In addition, the fact that the locations did not facilitate the speed of responding to the habitual travel mode indicates that location words are not semantically related to cycling per se. Hence, the presence of these location words in the previous experiments cannot account for our findings.

\section{General Discussion}

In the introduction, we defined habits as goal-directed automatic behaviors. Habits are mentally represented as associations between goals and actions. These associations are shaped by frequent performance of actions and require the activation of the goal to become manifest. The more frequently one engages in a certain goal-directed behavior in similar situations, the stronger the association becomes and, hence, the easier it is to automatically elicit the behavior by activating the goal. These ideas were supported in three experiments: Habitual responses were activated on the instigation of a goal. Furthermore, these same responses were not activated in the absence of the instigation of a goal, and they were not activated when they were not habitual.

In Experiment 2, we tested an additional hypothesis. In this experiment, we compared habitual goal-action associations with associations resulting from conscious planning, and some participants formed implementation intentions such as "I intend to perform action $x$ whenever situation $z$ occurs" (cf. Gollwitzer, 1993; Gollwitzer \& Brandstätter, 1997). These intentions are supposed to lead to the formation of associations between goals and actions and were hypothesized to be functionally equivalent to habitual associations. Indeed, participants who formed implementation intentions showed enhanced associative strength between travel goal and travel mode, just as did participants for whom the use of this travel mode was habitual. Our results indicate that this effect is manifest only when behavior is not habitual. Participants who had already developed strong habits did not benefit from planning. This makes sense because these participants already possessed strong links between goals and behavioral responses. With the formation of implementation intentions, people seem to be able to simulate goal-directed automaticity in habitual behavior (Gollwitzer, 1996; Orbell, Hodgkins, \& Sheeran, 1997). As such, these findings extend empirical investigations on the similarities between chronic and temporary sources of accessibility in the domain of social constructs and attitudes (Bargh et al., 1986; Fazio et al., 1986).

The theoretical significance of the present findings lies in the emphasis on the cognitive mechanism that mediates the often empirically established direct link between frequency of past behavior and later behavior (e.g., Aarts et al., 1998; Ouellette \& Wood, 1998). Our results in regard to automatic activation of associative links support the notion that frequently pursued goals (or habits) are mentally represented in a way comparable to other mental structures that are often repeatedly consulted and automatically activated, such as stereotypes and attitudes (e.g., Bargh \& Gollwitzer, 1994; Devine, 1989; Fazio et al., 1986; Kruglanski, 1996).

\section{Breaking Habits Through Planning}

Our studies are confined to the domain of travel behavior. However, although the present results cannot simply be general- 
ized to all kinds of frequently performed goal-directed behaviors, it is worthwhile to speculate on possible ways in which planning can help to break harmful or undesirable habits (e.g., drinking too much, eating the wrong foods, and applying social stereotypes). After all, our results suggest that associations between goals and actions that arise from frequent co-activation (i.e., habits) can be simulated by planning. Is it possible to "replace" one association with a different association?

Of course, planning can assist only on occasions in which the pursued goal can indeed be achieved by multiple actions (either objectively or subjectively assessed). If the habitual action is the only possible one, there is no alternative action one can or will plan. But let us restrict ourselves to goals that can be attained in multiple ways. As an example, imagine a person who always uses a car to travel from home to work and decides to use a bicycle instead. Can this person increase the probability of performing the counterhabitual intended action by planning this action? This is presumably dependent on the relative strength of the habitual association and the association that is the result of planning. It is likely that an association developed through planning can override a habitual association if the former is stronger.

In recent treatments of action control (e.g., Norman \& Shallice, 1986), it has often been argued that if multiple behavioral representations are activated, the one with the highest activation level will ultimately "win" the fight for dominance and guide overt behavior. This means that if goal activation leads to the activation of multiple behavioral representations (i.e., the habitual one and the planned one), the one with the highest activation level will guide overt behavior. The activation level of the alternative representations, in turn, is conditional on the strength of the associations between the activated goal and the different behavioral representation. An interesting avenue for further research would be to investigate how much planning is needed and what the content of the plan should be before planned behavior can override habitual behavior. Our results, which show that a little planning as to when, where, and how to achieve a goal is enough to create associations that are as strong as habitual associations (at least when the strength of these associations is measured soon after planning), are promising in this regard.

\section{Return of the Habit}

The concept of habit has a long-established history in theory and research. William James (1890) devoted an entire chapter to the concept of habit and the utility of habitual behavior. Early sociologists conceived of habits as behavioral patterns that serve as functional rules to control a society (e.g., Durkheim, 1893; see also Camic, 1986). They used a broad definition of habits to account for the stability of social institutions. The term habit was also used by theorists writing on evolutionary processes, who invoked the concept to denote the elementary behaviors of lower species. It was in this sense that Darwin (1859) wrote of such things as the "feeding habits of British insects." Darwin's work was related to the physiological literature of that time, revealing an interest in the movements of decapitated chickens, headless frogs, brainless cats, and the like. Later, the term was used for reflex actions, which were conceived as motor responses activated by nerve cells excited by stimuli external to the organism (Fearing, 1930).
In psychology, research on habits has long been dominated by behaviorist approaches to learning theory, typically providing a rather "mechanistic" account of the rise of behavioral responses (e.g., Skinner, 1938; Watson, 1914). That is, habits were merely conceptualized as automatic responses to stimulus cues with no consideration of the intervention of mental processes. However, this view was a bit rigid in the sense that it portrayed the actor as a victim of habitual programs, which seems rather unlikely from a functional point of view. As we have argued here, habits are goal directed, and their activation is dependent on goals (see also Hull, 1931; Tolman, 1932). People automatically enter the garage and take their car or bicycle only if there is a reason to do so (even though they may not be aware of this reason at the time of action).

Lately, the term habit has rarely been used as an explanatory concept in the psychology of human behavior (some exceptions to this rule can be found in the introduction). In our view, understanding of mundane behavior and even behavior in general can benefit greatly from the psychology of habits (Aarts, Paulussen, \& Schaalma, 1997; Verplanken \& Aarts, in press). At this time, many researchers consider human behavior as being guided by reasoning. Accordingly, much effort is devoted to trying to explain various, if not all, actions by studying the relations among attitudes, intentions, and behavior. We believe, however, that although the emphasis on more reason-based and deliberate processes is helpful for an understanding of certain behaviors, it is not the only useful concept for insight into behavior in general. Much of what people do in daily life becomes highly automatized. In these cases, consciousness has delegated the onset and the proceeding of behavior to the unconscious. We believe that in trying to explain what mode of transportation people choose, what they eat, drink, and smoke, and when and how they brush their teeth, habits will prove to be conceptually very useful tools. We therefore hope that the present analysis will contribute to the further development of the concept of habit.

\section{References}

Aarts, H., \& Dijksterhuis, A. (1999). How often did I do it: Experienced ease of retrieval and frequency estimates of past behavior. Acta Psychologica, 103, 77-89.

Aarts, H., Paulussen, T., \& Schaalma, H. (1997). Physical exercise habit: On the conceptualization and formation of habitual health behaviours. Health Education Research: Theory and Practice, 12, 363-374.

Aarts, H., Verplanken, B., \& van Knippenberg, A. (1998). Predicting behavior from actions in the past: Repeated decision making or a matter of habit? Joumal of Applied Social Psychology. 28, 1356-1375.

Anderson, J. R. (1982). Acquisition of cognitive skills. Psychological Review, 96, 369-406.

Anderson, J. R. (1993). Problem solving and learning. American Psychologist, 48, 35-44.

Austin, J. T., \& Vancouver, J. B. (1996). Goal constructs in psychology: Structure, process, and content. Psychological Bulletin, 120, 338-375.

Bargh, J. A. (1989). Conditional automaticity: Varieties of automatic influence in social perception and cognition. In J. S. Uleman \& J. A. Bargh (Eds.), Unintended thought (pp. 3-51). New York: Guilford Press.

Bargh, J. A. (1990). Auto-motives: Preconscious determinants of social interaction. In R. M. Sorrentino \& E. T. Higgins (Eds.), Handbook of motivation and cognition (pp. 93-130). New York: Guilford Press.

Bargh, J. A. (1997). The automaticity of everyday life. In R. S. Wyer (Ed.), Advances in social cognition (Vol. 10, pp. 1-61). Mahwah, NJ: Erlbaum. 
Bargh, J. A., Bond, R. N., Lombardi, W. J., \& Tota, M. E. (1986). The additive nature of chronic and temporary sources of construct accessibility. Journal of Personality and Social Psychology, 50, 869-878.

Bargh, J. A., Chaiken, S., Govender, R., \& Pratto, F. (1992). The generality of the automatic attitude activation effect. Journal of Personality and Social Psychology, 62, 892-912.

Bargh, J. A., \& Chartrand, T. L. (1999). A practical guide to priming and automaticity research. In H. Reis \& C. Judd (Eds.), Handbook of research methods in social psychology (871-932). New York: Cambridge University Press.

Bargh, J. A., \& Gollwitzer, P. M. (1994). Environmental control of goaldirected action: Automatic and strategic contingencies between situations and behavior. In W. D. Spaulding (Ed.), Nebraska Symposium on Motivation (Vol. 41, pp. 71-124). Lincoln: University of Nebraska Press.

Bargh, J. A., Gollwitzer, P. M., Chai, A. L., \& Barndollar, K. (1999). Bypassing the will: Nonconscious self-regulation through automatic goal pursuit. Manuscript submitted for publication.

Bargh, J. A., Raymond, P., Pryor, J. B., \& Strack, F. (1995). Attractiveness of the underlying: An automatic power $\rightarrow$ sex association and its consequences for sexual harassment and aggression. Journal of Personality and Social Psychology, 68, 768-781.

Bentler, P. M., \& Speckart, G. (1979). Models of attitude-behavior relations. Psychological Review, 452-464.

Camic, C. (1986). The matter of habit. American Journal of Sociology, 91 , 1039-1087.

Carver, C. S., \& Scheier, M. G. (1981). Attention and self-regulation: A control-theory approach to human behaviors. New York: SpringerVerlag.

Cohen, G. (1996). Memory in the real world. London: Taylor \& Francis.

Darwin, C. (1859). On the origin of species. Cambridge, MA: Harvard University Press.

Devine, P. G. (1989). Stereotypes and prejudice: Their automatic and controlled components. Journal of Personality and Social Psychology, 56, 5-18.

Durkheim, E. (1893). The division of labor in society (G. Simpson, Trans.). New York: Free Press.

Fazio, R. H., Sanbonmatsu, D. M., Powell, M. C., \& Kardes, F. R. (1986). On the automatic activation of attitudes. Journal of Personality and Social Psychology, 50, 229-238.

Fearing, F. (1930). Reflex action: A study in the history of physiological psychology. Baltimore: Williams \& Wilkins.

Fishbein, M., \& Ajzen, I. (1975). Belief, attitude, intention and behavior: An intraduction to theory and research. Reading, MA: Addison-Wesley.

Fitts, P. M., \& Posner, M. I. (1967). Human performance. Monterey, CA: Brooks/Cole.

Gallistel, C. R. (1985). Motivation, intention, and emotion: Goal-directed behavior from a cognitive-neuroethological point of view. In M. Frese \& M. Sabini (Eds.), Goul-directed behavior: The concept of action in psychology (pp. 48-66). Hillsdale, NJ: Erlbaum.

Geen, R. G. (1995). Human motivation. Pacific Grove, CA: Brooks/Cole. Gollwitzer, P. M. (1993). Goal achievement: The role of intentions. In W. Stroebe \& M. Hewstone (Eds.), European review of social psychology (Vol. 4, pp. 141-185). Chichester, England: Wiley.

Gollwitzer, P. M. (1996). The volitional benefits of planning. In P. M. Gollwitzer \& J. A. Bargh (Eds.), The psychology of action (pp. 287312). New York: Guilford Press.

Gollwitzer, P. M., \& Brandstätter, V. (1997). Implementation intentions and effective goal pursuit. Journal of Personality and Social Psychology, 73, 186-199.

Gollwitzer, P. M., \& Moskowitz, G. B. (1996). Goal effects on action and cognition. In E. T. Higgins \& A. W. Kruglanski (Eds.), Social psychology: Handbook of basic principles (pp. 361-399). New York: Guilford Press.
Hasher, L., \& Zacks, R. T. (1979). Automatic and effortful processing in memory. Journal of Experimental Psychology: General, 108, 356-388.

Higgins, E. T. (1996). Knowledge activation: Accessibility, applicability, and salience. In E. T. Higgins \& A. W. Kruglanski (Eds.), Social psychology: Handbook of basic principles (pp. 133-168). New York: Guilford Press.

Hull, C. L. (1931). Goal attraction and directing ideas conceived as habit phenomena. Psychological Review, 38, 487-506.

Hull, C. L. (1943). Principles of behavior: An introduction to behavior theory. New York: Appleton-Century-Crofts.

James, W. (1890). The principles of psychology. London: Macmillan.

Kruglanski, A. W. (1996). Goals as knowledge structures. In P. M. Gollwitzer \& J. A. Bargh (Eds.), The psychology of action (pp. 599-618). New York: Guilford Press.

Locke, E. A., \& Latham, G. P. (1990). A theory of goal-setting and task performance. Englewood Cliffs, NJ: Prentice Hall.

Mäntylä, T. (1993). Priming effects in prospective memory. Memory, I. 203-218.

Miller, G. A., Galanter, E., \& Pribram, K. H. (1960). Plans and the structure of behavior. New York: Holt, Rinehart \& Winston.

Mischel, W. (1973). Toward a cognitive social learning reconceptualization of personality. Psychological Review, 80, 252-283.

Mook, D. G. (1996). Motivation: The organization of action. New York: Norton.

Neely, J. (1977). Semantic priming and retrieval from lexical memory: Roles of inhibitionless spreading activation and limited-capacity attention. Journal of Experimental Psychology: General, 106, 226-254.

Neely, J. (1991). Semantic priming effects in visual word recognition: A selective review of current findings and theories. In D. Besner \& G. Humpreys (Eds.), Basic processes in reading: Visual word recognition (pp. 264-336). Hillsdale, NJ: Erlbaum.

Newell, A., \& Rosenbloom, P. (1981). Mechanisms of skill acquisition and the law of practice. In J. R. Anderson (Ed.), Cognitive skills and their acquisition (pp. 1-55). Hillsdale, NJ: Erlbaum.

Norman, D. A., \& Shallice, T. (1986). Attention and action: Willed and automatic control of behavior. In R. J. Davidson, G. E. Schwartz, \& D. Shapiro (Eds.), Consciousness and self-regulation: Advances in research and theory (Vol. 4, pp. 1-18). New York: Plenum.

Orbell, S., Hodgkins, S., \& Sheeran, P. (1997). Implementation intentions and the theory of planned behavior. Personality and Social Psychology Bulletin, 23, 945-954.

Ouellette, J., \& Wood, W. (1998). Habit and intention in everyday life: The multiple processes by which past behavior predicts future behavior. Psychological Bulletin, 124, 54-74.

Powers, W. T. (1973). Behavior: The control of perception. Chicago: Aldine.

Ronis, D. L., Yates, J. F., \& Kirscht, J. P. (1989). Attitudes, decisions, and habits as determinants of repeated behavior. In A. R. Pratkanis, S. J. Breckler, \& A. G. Greenwald (Eds.), Attitude structure and function (pp. 213-239). Hillsdale, NJ: Erlbaum.

Schank, R. C., \& Abelson, R. P. (1977). Scripts, plans, goals, and understanding. Hillsdale, NJ: Erlbaum.

Skinner, B. F. (1938). The behavior of organisms. New York: AppletonCentury-Crofts.

Smith, E. R., \& Lerner, M. (1986). Development of automatism of social judgments. Joumal of Personality and Social Psychology, 50, 246-259.

Srull, T. K., \& Wyer, R. S. (1986). The role of chronic and temporary goals in social information processing. In R. M. Sorrentino \& E. T. Higgins (Eds.), Handbook of motivation and cognition (pp. 503-549). New York: Guilford Press.

Thompson, E. P., Roman, R. J., Moskowitz, G. B., Chaiken, S., \& Bargh, J. A. (1994). Accuracy motivation attenuates covert priming: The systematic reprocessing of social information. Journal of Personality and Social Psychology, 66, 474-489. 
Tolman, E. C. (1932). Purposive behavior in animals and men. New York: Appleton-Century-Crofts.

Triandis, H. C. (1980). Values, attitudes, and interpersonal behavior. In H. E. Howe, Jr., \& M. Page (Eds.), Nebraska Symposium on Motivation (Vol. 27, pp. 195-259). Lincoln: University of Nebraska Press.

Vallacher, R. R., \& Wegner, D. M. (1987). What do people think they"re doing? Action identification and human behavior. Psychological Review, 94, 3-15.

Verplanken, B., \& Aarts, H. (in press). Habit, attitudes, and planned behaviour. Is habit an empty construct or an interesting case of goal- directed automaticity? In W. Stroebe \& M. Hewstone (Eds.), European review of social psychology. Chichester, England: Wiley.

Watson, J. B. (1914). Behavior: An introduction to comparative behavior. New York: Holt.

\section{Low Publication Prices for APA Members and Affiliates}

Keeping you up-to-date. All APA Fellows, Members, Associates, and Student Affiliates receive-as part of their annual dues-subscriptions to the American Psychologist and APA Monitor. High School Teacher and International Affiliates receive subscriptions to the APA Monitor, and they may subscribe to the American Psychologist at a significantly reduced rate. In addition, all Members and Student Affiliates are eligible for savings of up to $60 \%$ (plus a journal credit) on all other APA journals, as well as significant discounts on subscriptions from cooperating societies and publishers (e.g., the American Association for Counseling and Development, Academic Press, and Human Sciences Press).

Essential resources. APA members and affiliates receive special rates for purchases of APA books, including the Publication Manual of the American Psychological Association, and on dozens of new topical books each year.

Other benefits of membership. Membership in APA also provides eligibility for competitive insurance plans, continuing education programs, reduced APA convention fees, and specialty divisions.

More information. Write to American Psychological Association, Membership Services, 750 First Street, NE, Washington, DC 20002-4242. 